\title{
The Composition of Family Background: The Influence of the Economic and Cultural Resources of both Parents on the Offspring's Educational Attainment in the Netherlands between 1939 and 1991
}

\author{
Maarten L. Buis* \\ Abstract: This article studies the effect of parental background on the educational attainment of \\ the offspring. In particular, it compares the effects of parental occupation and education and \\ investigates whether the relative importance of these resources have shifted over time. In addition, \\ this article studies, which parent has the strongest effect on the offspring's education. Using data \\ for the Netherlands, this article finds that occupational status has the same effect regardless of who \\ contributed it, while for the effect of parental education, it matters whether the parent is the \\ highest, same, or lowest educated parent. No evidence was found that the relative sizes of these \\ effects have changed over cohorts.
}

\section{Introduction}

Studying the effect of family background on educational attainment has a long history (for a review, see: Breen and Jonsson, 2005). One question that such studies need to ask is what characteristics of the family influence educational attainment. In this article, I focus on the fact that family background is a multidimensional concept in the sense that families have different types of resources available, which are contributed by both parents. The relative influences of these resources and whether or not these relative influences changed over time can give a richer picture of the changing influence of families on the education of their offspring. Moreover, such an analysis can help finding out if much of the existing research in this area suffers from a methodological problem. It is relatively common for studies on this topic to use only one indicator for family background, most commonly based on the occupation of the father (for a recent example, see: Breen et al., 2010). This could be a problem if the influence of the father has declined relative to that of the mother. In that case, the decline in the effect of fathers' background that has often been found in the Netherlands (e.g. De Graaf and Ganzeboom, 1993) and more recently in other countries (e.g. Breen et al., 2010) could just be caused by the fact that fathers' characteristics are an increasingly bad indicator for family background (Beller, 2009). A similar problem could occur if the more economic resources associated with parents' occupation become less important com pared to the more social and cultural resources associated with parents' education.

This article studies the relative influence of the following resources: occupational status and education of both the father and the mother. This will be done by answering the following two questions: first, how important was each parent's contribution to the off spring's education in the Netherlands between 1939 and 1991? Secondly, did the relative contributions of parental education and occupational status to the offspring's educational attainment change in the Netherlands between 1939 and 1991 ?

Department of Sociology, University of Tubingen, Wilhelmstraße 36, 72074 Tubingen, Germany. ${ }^{\star}$ Corresponding author. Email: maarten.buis@uni tuebingen.de 


\section{Parental Resources and their Effect on the Offspring's Education}

A useful way of bringing order to the multidimensional nature of family background is to make a distinction between who is contributing resources and what is being contributed.

The most obvious comparison when describing who is contributing resources is the comparison between the father and the mother, but this may not be the most relevant comparison; other alternatives are: the parent of the same sex as the offspring versus the parent of the other sex, and the parent with the highest education or occupation versus the parent with the lowest education or occupation. Moreover, these possibilities are not mutually exclusive; for instance, the fact that the father has an effect does not preclude the highest educated parent from having an effect as well (Korupp, Ganzeboom and Van der Lippe, 2002).

As well as who contributes resources, this article also studies what is contributed. In particular, two types of resources that each parent can contribute will be considered: the highest achieved level education of the parent and the parent's occupational status.

\section{Which Resource?}

The bulk of the literature in this area uses parental occupation, parental education, or both (Breen and Jonsson, 2005). The justification for using these variables is typically based on more than one mechanism through which these variables can influence the educational attainment of the offspring. The main mechanisms are discussed below with particular emphasis on whether or not one can expect a change in the strength of these mechanisms over time.

\section{Occupation}

Parental occupation can influence the children's educa tion through the fact that an occupation is an important means of improving the material circumstances of the family (Goldthorpe, 1983; Erikson, 1984), which in turn can be used to help pay for the cost of education. These costs can be the direct cost of education in the form of tuition fees, books, etc. They can also be indirect cost of education like opportunity costs, that is, the income someone is not earning while he or she is in education rather than working (De Graaf, De Graaf and Kraaykamp, 2000). Economic resources can also help by providing an environment that is conducive for attaining education, for example, a house that is big enough so that all children can have a quiet space where they can do their homework (Murnane, Maynard and Ohls, 1981). However, the direct and indirect costs of education are relatively small in the Netherlands due to egalitarian policies. The results of these policies are that primary and four years of secondary education are largely free, there are means tested grants for the subsequent years of education, and there is little opportunity to buy better education by sending children to an expensive and/or exclusive private school, as the number of such schools is negligible and their merit is not widely recognized (De Graaf, De Graaf and Kraaykamp, 2000). These egalitarian policies were not all implemented at once, and financial constraints may well have been more an issue for the earliest cohorts studied in this article (De Graaf, 1986; De Graaf and Ganzeboom, 1993; De Graaf, De Graaf and Kraaykamp, 2000). The ability to buy or rent a house of sufficient size could be another possible cause of a declining trend in the effect of parental occupation. During the period shortly after the Second World War, there was a severe housing shortage, which only gradually decreased (Boelhouwer, 2002; Mulder and Hooimeijer, 2002). This leads again to the prediction that material resources were probably more an issue for the oldest cohorts than for the youngest cohorts.

Another mechanism is that some occupations are inherently less stressful than others, in the sense that they may entail more job security, more opportunity for upward mobility, or less non standard working hours (Erikson, 1984). Such work conditions can influence the atmosphere at home and the quality of the relationship between the parents, and even lead to or prevent divorce (Weiss and Liss, 1988; White and Keith, 1990; Perry Jenkins et al., 2007), which in turn can influence the performance of children in school and thus the educational attainment of these children (Furstenberg and Kiernan, 2001; Menning, 2002). The amount of stress from the working conditions associated with an occupation is likely to be alleviated by the welfare state by regulating work conditions, and providing a safety net and services that help balance the demands from work and family (Mills and Taht, 2010). This study covers a period in which these provisions were expanded. As a consequence, one may again expect that the effect of parental occupation has declined over time.

\section{Education}

Parental education can directly influence the education of the children in that higher educated parents are likely to be more effective when trying to help their children do well at school. Higher educated parents may also be 
more effective in influencing decisions of their children and school officials when transitions between levels of educations take place (Lucas, 2001; Deil Amen and Rosenbaum, 2003). This may be especially relevant in stratified educational systems like the Netherlands, where students are assigned to different tracks at the age of 12 years (Lucas, 2001). In such a system, one can expect parents to play a more important role than in systems where the key decision is made when children are older, as older children are less dependent on their parents (Muller and Karle, 1993). The strength of this mechan ism might have decreased, if schools have become more effective in preparing children for school, thus neutraliz ing the disadvantage experienced by children of lower educated parents. However, attaining and maintaining such a high level of effective teaching is hard, and higher educated parents will adept, and as a consequence maintain the relative advantage for their children (Lucas, 2001). For this effect to take place, there is no need to assume any malice on the part of higher educated parent, they may just, legitimately, want to help their children do well at school. For this reason, I expect the effect of education to decline less over time than the effect of occupation.

A more general mechanism is that higher educated parents tend to have and transmit more cultural resources, which can help the children perform well at school (Bourdieu, 1973). This cultural capital might influence educational attainment in two ways (De Graaf, De Graaf and Kraaykamp, 2000). First, more cultural capital means that a child tends to have the language and dialect, cultural preferences, and ways of interacting with others that are viewed positively by teachers. This will influence the performance of the children, both because these children are less likely to view school as a hostile environment, and because these characteristics are posi tively sanctioned by teachers (Lareau, 1987). This aspect of social capital is most associated with tastes for and participation in highbrow culture, and will be most important in countries like Italy and France, where highbrow cultural aspects are relatively important in the curriculum (De Graaf, De Graaf and Kraaykamp, 2000). Secondly, having more cultural capital is also associated with developing reading habits and acquiring linguistic skills (Farkas, 1996). This aspect of cultural capital is likely to be especially important in countries like the Netherlands, where there is a strong emphasis on teaching (modern) foreign languages (De Graaf, De Graaf and Kraaykamp, 2000). This emphasis on foreign languages has not changed over time, so again I do not expect a major change over time in the strength of this mechanism.

\section{Which Parent?}

Many families consist of more than one parent, so one may ask which parents' education or occupation counts (most) as the family's education or occupation? The dominant approach is to choose the father's character istics, but one might expect that this is an imperfect approximation of the resources available to a family. If one wants to include a characteristic of both parents, one may want to allow for the possibility that not every parent is equally important. For example, one may have the hypothesis that the father's characteristics are more important for the sons while the mother's characteristics are more important for the daughters. Below, I will discuss three sets of such hypotheses.

The first set is based on the gender of the parent alone. The most important hypothesis of this type is the 'conventional view' (Goldthorpe, 1983) that a family's occupational status can be derived from the occupational status of the father alone. The logic behind this view is based on the conventional role model in which married women are made responsible for a large share of the work that needs to be done in order to maintain the family and raise the children. As a consequence, many women have had to sacrifice some or all occupational success, leading to the prediction that men are the dominant source of occupational status in most families.

However, this choosing one parent as the 'represen tative parent' does not fit well with the main mechan isms behind the effect of occupational status. When parents' occupations affect childrens' education through material resources earned, then it makes sense to consider the sum of resources contributed by both parents rather than choosing one parent as the repre sentative parent (Beller, 2009). Similarly, if parental occupation works through the (lack of) stress due to the working conditions in an occupation, then it again makes sense to also think of these effects in additive terms. This leaves the practical problem that occupa tional status, and especially occupational class, is often measured on a scale that makes it hard to add them. One can solve this by including the occupation of both parents. Moreover, one can constrain their effects to be equal when one assumes that it is the resources and/or stress that are brought into the family that matter and not who brings them in. ${ }^{1}$

Another problem with the conventional view is that it does not generalize well to parental education. If parental education works either through helping children do well at school or through the transmission of cultural capital, then one may expect that the effectiveness of parental education depends on the amount of time spent with the children. Since the traditional pattern is that it is the 
mother who spends most time with the children, one may expect that mother's education has the stronger effect rather than the father's. This difference is likely to be less pronounced in families where the mother also works.

The second set of hypotheses is based on what is sometimes called the 'dominance model' (Erikson, 1984), which postulates that it is the parent with the highest status that determines the familys' class position. The justification of this model can be based on the 'power model' by McDonald (1977), which assumes that these differences in status represent differences in power within the family, and that children are influenced by the most powerful parent. It is useful to make a distinction between a strong and weak version of this hypothesis. The strong version of this hypothesis is that it is only the parent with the highest occupation or education that matters. One can weaken this hypothesis by stating that both parents matter, but that the parent with the highest occupation or education matters most.

The third set of hypotheses is based on the sex role model, which assumes that daughters are primarily oriented towards their mother and sons towards their father because the same sex parent is perceived by the children to have more relevant information for their situation (Acock and Yang, 1984; Boyd, 1989). One can again make the distinction between a strong and a weak version of the hypothesis, where the strong version would state that it is only the same sex parent that matters, while the weak version states that both parents matter, but that the same sex parent matters most.

\section{Predictions}

The discussion above leads to the following predictions:

1. the effect of parental occupations declines faster than the effect of parental education, that is, the contri bution of parental education relative to parental occupation is expected to increase;

2. both father's and mother's occupation will influence their children's education, and their effects are the same;

3. the effect of the parent with the highest education or occupation is larger than the effect of the parent with the lowest education or occupation;

4. the effect of the parent with the same sex as the child will be larger than the effect of the parent with the opposite sex as the child; and

5. the effect of the mother's education will be stronger than the effect of the father's education, if the mother does not work, and this difference is smaller when both parents work.

\section{Previous Findings}

There is clear empirical evidence that in the Netherlands both parental education and parental occupation have independent effects on the educational attainment of the offspring (De Graaf and Ganzeboom, 1993; Ganzeboom, Kalmijn and Peschar, 1995; Sieben, Huinink and De Graaf, 2001; Gesthuizen, De Graaf, Kraaykamp, 2005). Evidence has been found that parental occupation became relatively less important when compared to parental education over time in the Netherlands (De Graaf and Ganzeboom, 1993; Ganzeboom, Kalmijn and Peschar, 1995). However, these studies have not been able to formally test this hypothesis.

There is previous research that shows that mothers' characteristics do have an effect independent of the fathers' characteristics in the Netherlands (Dronkers, 1995; Korupp, Ganzeboom and Van der Lippe, 2002; Marks, 2008a). However, in the Netherlands no evidence has been found that including mothers in the analysis leads to changes in conclusions regarding the trend in educational inequality (Korupp, Ganzeboom and Van der Lippe, 2002). There is also some evidence that father's occupational status is more important than mother's occupational status, while mother's education is more important than father's education (Marks, 2008a). Support has been found for a version of the dominance model that includes both the dominant and the non dominant parent (Korupp, Ganzeboom and Van der Lippe, 2002). However, there is little empirical support for the sex role model (Dronker, 1995; Korupp, Ganzeboom and Van der Lippe, 2002; Marks, 2008b). Of these studies, only the study by Korupp, Ganzeboom and Van der Lippe (2002) investigates all three hypotheses concerning which parent matters. However, they only study these hypotheses in isolation.

\section{Data and Method}

\section{Data}

The data consist of 11 surveys $^{2}$ that collected informa tion from respondents in the Netherlands on the highest achieved level of education of the respondents, as well as the highest achieved level of education and occupational status of their father and mother. All these surveys have been post harmonized by Ganzeboom and Treiman (Ganzeboom and Treiman, 2009) as part of the International Stratification and Mobility File, ISMF. Together, these surveys contain information on 
approximately 11,500 respondents with complete infor mation on father's occupational status, and father's, mother's, and own education. ${ }^{3}$ These data cover the period between 1939 and 1991, as measured by the year in which the respondent was 12 (at around this age, students in the Netherlands make the most important choice in their educational career).

The highest achieved level of education of the respondents and their fathers and mothers are measured in pseudo years, using the scale estimated by Buis (Buis, 2010: ch. 3). This scale assigns values to educational categories such that it best predicts the respondent's later occupational status. Primary education was assigned the value 6 and university the value 17 to identify the origin and unit of the scale. As a consequence, the scale can be interpreted in terms of pseudo years of education. The highest achieved level of education of the father and the mother has been rescaled such that it ranges between zero and one. The occupational status of the parents was measured in terms of the International Socio Economic Index of occupational status (ISEI; Ganzeboom and Treiman, 2003) and has also been rescaled to range between zero and one.

In this article, a mother is considered to have always been a homemaker if there is no information on her occupation. ${ }^{4}$ Homemakers are included in the analysis by setting their occupational status to zero, and adding a variable to the model indicating whether or not the mother is a homemaker. The dummy for homemaker measures how much education respondents would have gained or lost if their mother had always been a homemaker rather than having the lowest status job. An interaction between the father's occupation and the homemaker dummy is added to allow the effect of the father's occupational status to change when the father is the only person in the household to bring in occupa tional status. An interaction between the mother's education and the homemaker dummy is also added, to allow the effect of the mother's education to change when mother's education is her only source of status.

To capture the different ways in which both parents could influence the respondent's education, the following sets of variables are added to the model:

- The education and occupation of the father and the mother.

- The education and occupation of the parent with the highest education or occupational status, and the education and occupation of the parent with the lowest education or occupation. This means the reference category consists of parents who both have the same level of education or occupational status. Occupational statuses are considered to be equal when they differ by less than 10 ISEI points, while education is considered equal if parents had attained the same educational category.

- The education and occupation of the parent with the same sex as the respondent, which means that the reference category is the parent of the opposite sex as the respondent. In case of female respondents, the occupation of the same sex parent could be home maker, so an interaction between the sex of the respondent and the homemaker indicator variable is also part of this set of variables.

Thus, the main effects of education of the father and the mother represent the effects when the father and the mother have the same education, and when the respondent has the opposite sex to the parent. Similarly, the main effects of the occupational status of the father and the mother are the effects when the difference in occupational status between the father and the mother is less than 10 ISEI points and when the respondent has the opposite sex to the parent. All the other educational and occupational variables measure the difference in effects compared with these reference categories.

Time is measured by the year in which the respondent was 12 . This is seen as the best approximation of when any effect occurs because it is at approximately that age when students in the Netherlands are streamed in different tracks within secondary education, which will have major consequences for their subsequent educa tional career. The unit of the time variable is decades since 1940. To allow for a non linear trend, this variable is entered in the model as linear spline with a knot at $1970 .^{5}$

\section{Method}

Testing the first prediction requires a special model to test whether the relative impact of the different parental resources on the offspring's education changed over time. This is done by estimating a regression with parametrically weighted explanatory variables (Yamaguchi, 2002). This model represents the null hypothesis that the effects of the parental resources may have changed over time, but that the relative impact of each of these resources has remained constant. The method can be illustrated using the following simplified example: The respondent's education (ed) is influenced by parental education (ped) and parental occupational status (pocc), and these effects are allowed to change over time $(t)$, as in equation (1).

$$
\text { ed } \quad \beta_{0}+\beta_{2} t+\left(1+\beta_{3} t\right)\left(\gamma_{1} \text { ped }+\gamma_{2} \text { pocc }\right)+\varepsilon
$$


According to this equation, the effect of ped is $\left(1+\beta_{3} t\right) \gamma_{1}$ and the effect of pocc is $\left(1+\beta_{3} t\right) \gamma_{2}$. So, the effects of these variables are allowed to change over time, but the relative size of these effects, $\left[\left(1+\beta_{3} t\right) \gamma_{1}\right] /$ $\left[\begin{array}{lll}\left(1+\beta_{3} t\right) & \gamma_{2}\end{array} \quad \gamma_{1} / \gamma_{2}\right.$, is constrained to remain constant over time. This is a so called proportionality constraint.

The model in equation (1) can be estimated with maximum likelihood, if we make the standard assump tion that the error term $(\varepsilon)$ is normally distributed with mean 0 and a constant variance. If these assumptions are made, the alternative hypothesis, which relaxes the proportionality constraint, would then be represented by a normal linear regression with interactions between $t$ and pedd and $t$ and pocc. The test of the null hypothesis that the relative impact of these resources has remained constant over time is then the likelihood ratio test comparing these two models. This is implemented in Stata (StataCorp, 2011) as the propcnsreg package (Buis, 2007).

\section{Results}

The analysis started with a test of the first prediction, that is, whether the relative sizes of the influence of parental occupation has declined compared to parental education. ${ }^{6}$ A test of the null hypothesis that these relative effects have remained constant resulted in a likelihood ratio $\chi^{2}$ value of 50.16 , with 47 degrees of freedom, leading to a $P$ value of 0.349 , which means that the null hypothesis cannot be rejected. In other words, no evidence was found to support the first prediction.

The remaining predictions were tested using the models shown in Table 1. Table 1 consists of three main panels: labelled 'constrained', 'trend', and 'main'. The parameter estimates in the panel labelled 'con strained' refer to the effect of parental resources on the respondent's highest attained level of education for men (Model 1) or men and women (Model 2) from the cohort aged 12 in 1940. The panel labelled 'trend' displays the change in effect of the parental resource variables over time and between men and women (Model 1) or only over time (Model 2). The panel labelled 'main' captures the effects of other variables that influence educational background.

The next step in the analysis is to investigate which parent matters most. Model 1 simultaneously allows all hypothesized ways in which parents can affect their children. These effects were tested and these tests are reported in Table 2. The first row in this table reports the test that only the father matters, this is the conventional hypothesis by Goldthorpe (1983). This hypothesis is rejected for both the parental education and the parental occupational status. The second row
Table 1 Parameter estimates of models explaining highest achieved level of education

\begin{tabular}{|c|c|c|}
\hline & $\begin{array}{c}\text { Model } 1 \\
b \text { (SE) }\end{array}$ & $\begin{array}{c}\text { Model } 2 \\
b(\mathrm{SE})\end{array}$ \\
\hline \multicolumn{3}{|l|}{ Constrained } \\
\hline \multicolumn{3}{|l|}{ Occupation } \\
\hline Father & $3.347(0.50)$ & $3.331^{\mathrm{a}}(0.24)$ \\
\hline Mother & $2.503(0.49)$ & $3.331^{\mathrm{a}}(0.24)$ \\
\hline Highest & $0.012(0.44)$ & \\
\hline Lowest & $0.126(0.62)$ & \\
\hline Same sex & $0.449(0.44)$ & \\
\hline Homemaker & $0.727(0.23)$ & $0.611(0.21)$ \\
\hline Home $\times$ female & $0.445(0.22)$ & \\
\hline Home $\times$ father & $1.344(0.52)$ & $1.905(0.42)$ \\
\hline \multicolumn{3}{|l|}{ Education } \\
\hline Father & $2.348(0.33)$ & $2.396^{\mathrm{b}}(0.19)$ \\
\hline Mother & $2.069(0.36)$ & $2.396^{\mathrm{b}}(0.19)$ \\
\hline Highest & $1.012(0.25)$ & $1.207(0.22)$ \\
\hline Lowest & $0.961(0.40)$ & $1.109(0.40)$ \\
\hline Same sex & $0.087(0.34)$ & \\
\hline Home $\times$ mother & $0.975(0.44)$ & $0.918(0.44)$ \\
\hline \multicolumn{3}{|l|}{ Trend } \\
\hline Year $_{1939-1970}$ & $0.121(0.02)$ & $0.135(0.01)$ \\
\hline Year $_{1970-1991}$ & $0.005(0.04)$ & $0.002(0.03)$ \\
\hline Female & $0.122(0.10)$ & \\
\hline Female $\times$ year $_{1939-1970}$ & $0.046(0.04)$ & \\
\hline Female $\times$ year $_{1970-1991}$ & $0.007(0.06)$ & \\
\hline Constant & 1.000 & 1.000 \\
\hline \multicolumn{3}{|l|}{ Main } \\
\hline Year $_{1939-1970}$ & $0.453(0.10)$ & $0.517(0.08)$ \\
\hline Year $_{1970-1991}$ & $0.213(0.21)$ & $0.185(0.16)$ \\
\hline Female & $2.164(0.35)$ & $1.702(0.20)$ \\
\hline Female $\times$ year $_{1939-1970}$ & $0.573(0.15)$ & $0.414(0.09)$ \\
\hline Female $\times$ year $_{1970-1991}$ & $0.287(0.29)$ & $0.216(0.14)$ \\
\hline Constant & $8.143(0.26)$ & $7.988(0.22)$ \\
\hline Log likelihood & $29,966.2$ & $29,971.2$ \\
\hline$N^{\circ}$ & 11,907 & 11,907 \\
\hline
\end{tabular}

${ }^{a, b}$ Entries with the same superscript are constrained to be equal.

tests whether father's resources have the same effects as mother's resources. This hypothesis cannot be rejected for parents' occupation nor for parents' education, thus supporting the second prediction. The third row tests the dominance hypothesis: whether the effect of the parent with the highest education or occupational status differs from the effects when both parents have the same occupational status or education, and whether the effects of the parents who both have the same education or occupational status differs from the effect of the parent with the lowest education or occupational status. The hypothesis that these effects are the same must be rejected for the education of the parents, but this is not the case for the parents' occupational status, indicating 
Table 2 Constraints on the effects of parental resources (Wald tests)

\begin{tabular}{|c|c|c|c|c|c|c|}
\hline \multirow{2}{*}{ Null hypothesis } & \multicolumn{3}{|c|}{ Occupation } & \multicolumn{3}{|c|}{ Education } \\
\hline & $\chi^{2}$ & df & $P$ & $\chi^{2}$ & df & $P$ \\
\hline Female 0 & 25.67 & 1 & 0.000 & 32.83 & 1 & 0.000 \\
\hline Father mother & 1.64 & 1 & 0.201 & 0.44 & 1 & 0.507 \\
\hline Highest same lowest & 0.12 & 2 & 0.941 & 16.50 & 2 & 0.000 \\
\hline Same sex different sex & 4.33 & 2 & 0.115 & 0.07 & 1 & 0.793 \\
\hline Homemaker $\times$ resource $^{\mathrm{a}} \quad 0$ & 6.65 & 1 & 0.010 & 4.91 & 1 & 0.027 \\
\hline
\end{tabular}

${ }^{a}$ For occupation the resource refers to the father, for education the resource refers to the mother.

partial support for the third prediction. The fourth row tests the sex role hypothesis: whether the effect of the mother on the daughter and the father on the son is different from the effect of the mother on the son and the father on the daughter. ${ }^{7}$ The hypothesis of no sex role effect could not be rejected for both the effect of parental education and occupational status. This pro vides evidence against the fourth prediction. Finally, the fifth row tests the hypothesis that the effect of father's occupation and mother's education do not change when the mother is a homemaker. This hypothesis could not be rejected for both education and occupation, which provides support for the fifth prediction.

Model 1 can be further simplified by forcing the effects of the resources to be the same for male and female respondents, that is, constraining the effects of female, female $\times$ year ${ }_{1939-1970}$, and female $\times$ year $_{1970-1991}$ in the second panel of Table 1 to be zero. All these constraints together result in the simplified Model 2 in Table 1. The parameters can be interpreted in the following way: within the subpanel labelled 'occupation', the parameters for father and mother are the effects of the father's and mother's occupational status on the respondent's education in 1940, if the mother was not a homemaker. It shows that if a parent moves from the lowest to the highest status occupation, the offspring's education is expected to increase by 3.3 pseudo years. The effect of the variable homemaker indicates the difference in education between respondents whose mother has always been a homemaker and those whose mother had a job with the lowest status. The offspring is likely to attain 0.6 pseudo years more education when the mother had the lowest status job as opposed to being a homemaker. The effect of home $\times$ father shows that when the mother was a homemaker, the father's occupational status increases by about 1.9 pseudo years. This means that the negative effect of the mother being a homemaker can be decreased or even reversed by an increase in the father's occupational status. The subpanel labelled 'education' shows that increasing a parent's education from the lowest to the highest level results in an increase in the offspring's education by 2.4 pseudo years if the father and the mother have the same education, and that this effect increases by 1.2 pseudo years if the parent is the highest educated parent, and decreases by 1.1 pseudo years if the parent is the lowest educated parent. The effect of the interaction term home $\times$ mother shows that if the mother was a homemaker, the effect of her education increases by 0.9 pseudo years. As a consequence, the effect of the mother being a homemaker can become less negative or even positive when the mother has a higher level of education.

The panel labelled 'trend' indicates how the effects of the parental background variables changed over time. Between 1939 and 1970, the effects described above declined by 13.5 per cent per decade. After 1970, the effects remained constant. The panel labelled 'main' showed that in 1940 men with parents who had the lowest possible level of education and occupation and whose mother worked could expect to attain about 8 pseudo years of education (the constant), while women could expect 1.7 pseudo years less. Before 1970, this increased by about 0.5 pseudo years per decade for men and 0.9 pseudo years per decade for women (year ${ }_{1939-}$ $1970+$ female $\times$ year $\left._{1939-1970}\right)$. After 1970, neither the trend for men nor the trend for women was significant anymore.

\section{Conclusions and Discussion}

This article started with the notion that parents have multiple resources available with which they can help their offspring. This article focused on two of these: parental education and parental occupational status. Two questions were asked: first, how important was each parent's contribution to the offspring's education in the Netherlands between 1939 and 1991? Secondly, did the relative contributions of parental education and 
occupational status to the offspring's educational attain ment change in the Netherlands between 1939 and 1991?

These questions were made more concrete by specify ing the following predictions:

1. the effect of parental occupations declines faster than the effect of parental education, that is, the contri bution of parental education relative to parental occupation is expected to increase;

2. both father's and mother's occupation will influence their children's education, and their effects are the same;

3. the effect of the parent with the highest education or occupation is larger than the effect of the parent with the lowest education or occupation;

4. the effect of the parent with the same sex as the child will be larger than the effect of the parent with the opposite sex as the child; and

5. the effect of mother's education will be stronger than the effect of father's education if the mother does not work, and this difference is smaller when both parents work.

Support was found for the second and fifth prediction and partial support was found for the third prediction, but no support was found for the first and the fourth prediction. In particular, the analysis showed that as long as the mother works, it does not matter who brings in the resources (Prediction 2). This provides evidence against Goldthorpe's (1983) 'conventional view' and supporting the idea that the recourses from both parents have a cumulative effect. In addition, support was found for the weak version of the dominance model (Prediction 3). No support was found for the sex role model (Prediction 4). Having a mother who has been a homemaker decreases the respondent's expected level of education compared to respondents from mothers with the lowest status job. However, the effect of the mother being a homemaker on the offspring's education be comes positive when the mother is highly educated and/ or the father has a high status job, thus supporting Prediction 5.

The impact of occupational status was expected to decline relative to parental education (Prediction 1), but no such changes were found in this study. A possible reason for this could be lack of statistical power. The test of this hypothesis was a test that the effects of all the resources on the offspring's education changed over time in such a way that the relative differences in effect remained constant. This is a rather subtle constraint, and a test of this constraint is thus a test with a rather low statistical power.
The two main findings of this article are that it matters relatively little which parent brings in the resources as long as the mother works, and that no evidence was found that the relative contributions of different family resources have changed over time. The lack of evidence for a change in the relative contribu tions was not expected, but it has a fortuitous practical consequence for social stratification and mobility re search: a significant part of this literature has used only a single indicator of parental resources to estimate the effect of family background on educational attainment of the offspring, most commonly the father's occupational status. A negative trend in the effect of the father's occupational status would in that case be open to a number of interpretations: either the educational system has become more open to people from different backgrounds, or the father's occupational status has become an increasingly bad proxy for family background as fathers have lost influence relative to mothers, or the father's occupational status may have become less important but other family background characteristics, like education, may have remained constant or even increased in importance. However, no evidence was found for the second interpretation. So, the use of a single indicator for family background is still a reason able strategy, especially when only one indicator is present in the data.

\section{Notes}

1 Constraining the effects of two variables to be the same is actually mathematically equivalent to estimating the effect of the sum of these two variables even though the substantive justification and interpretation is quite different. Consider the relevant part of the regression equation: $\beta_{1} x_{1}+\beta_{2}$ $x_{2}$. Constraining the effects of $x_{1}$ and $x_{2}$ to be equal means one can replace $\beta_{1}$ and $\beta_{2}$ with $\beta: \beta x_{1}+\beta$ $x_{2}$, which can be rewritten as: $\beta\left(x_{1}+x_{2}\right)$.

2 These surveys are: net92f, net94h, net95h, net95y, net96, net96y, net98, net98f, net99, net04i, and net06i, where the codes refer (Ganzeboom and Treiman, 2009).

3 The percentage of missing values was: for father's occupation 6.4 per cent, for father's education 5.2 per cent, for mother's education 4.7 per cent, and for own education 0.7 per cent. Together, 10.8 per cent of the observation had at least one missing value on any of these variables. 
4 This means that mothers who either had a genuine missing value or were unemployed will be misclassi fied as homemakers. The latter problem is diminished a bit by the fact that these surveys typically asked about the mother's occupation when the respondent was 16 years old. So if the mother had a job at any point in that year, the respondent would have given that occupation as an answer. As a consequence, only women who are unemployed for longer than a year will be wrongfully classified as homemaker.

5 The year 1970 was chosen as this approximately corresponds with the break in trend found using different methods in the same data (Buis, forthcoming).

6 The model with the proportionality constraint is presented as Model 1 in Table 1, while the parameter estimates of the unconstrained model are not shown due to the large number of param eters in this model.

7 Note that the effect of the occupation of the parent with the same sex as the respondent is captured by two variables: the occupational status of the same sex parent and the interaction between homemaker and female. So this is a 2 degree of freedom test for occupation and a 1 degree of freedom test for education.

\section{References}

Acock, A. C. and Yang, W. S. (1984). Parental power and adolescents' identification. Journal of Marriage and the Family, 46, 487495.

Beller, E. (2009). Bringing intergenerational social mo bility research into the twenty first century: why mothers matter. American Sociological Review, 74, 507528.

Boelhouwer, P. (2002). Trends in Dutch housing policy and the shifting position of the social rented sector. Urban Studies, 39, 219235.

Bourdieu, P. (1973). Cultural reproduction and social reproduction. In Brown, R. (Ed.), Knowledge, Education and Cultural Change. London: Travistock.

Boyd, C. J. (1989). Mothers and daughters: a discussion of theory and research. Journal of Marriage and the Family, 51, 291301.

Breen, R. and Jonsson, J. O. (2005). Inequality of opportunity in comparative perspective: recent re search on educational and social mobility. Annual Review of Sociology, 31, 223243.
Breen, R. et al. (2010). Long term trends in educational inequality in Europe: class inequalities and gen der differences. European Sociological Review, 26, 3148.

Buis, M. L. (2007). Propcnsreg: Stata module fitting a measurement model with causal indicators. Available from <http://econpapers.repec.org/software/bocbocode/ s456858.htm > [accessed 16 March 2010].

Buis, M. L. (2010). Inequality of Educational Outcome and Inequality of Educational Opportunity in the Netherlands during the 20th Century. PhD thesis, Faculty of Social Sciences, VU University Amsterdam.

Buis, M. L. (forthcoming). Lange termijn trends in onderwijsongelijkheid in Nederland [Long term trends in educational inequality in the Netherlands]. In Van de Werfhorst, H. G. and Ganzeboom, H. B. G. (Eds.), Onderwijs en Stratificatie: Ongelijkheid, Arbeidsmarkt en Participatie in de Afgelopen Decennia [Education and Stratification: Inequality, Labor Market and Participation in the last Decades]. Amsterdam: Amsterdam University Press.

Deil Amen, R. and Rosenbaum, J. E. (2003). The social prerequisites of success: can college structure reduce the need for social know how? The Annals of the American Academy of Political and Social Science, 586, 120143.

De Graaf, P. M. (1986). The impact of financial and cultural resources on educational attainment in the Netherlands. Sociology of Education, 59, 237246.

De Graaf, N. D., De Graaf, P. M. and Kraaykamp, G. (2000). Parental cultural capital and educational attainment in the Netherlands: a refinement of the cultural capital perspective. Sociology of Education, 73, 92111.

De Graaf, P. M. and Ganzeboom, H. B. G. (1993). Family background and educational attainment in the Netherlands for the1891 1960 birth cohorts. In Shavit, Y. and Blossfeld, H. P. (Eds.), Persistent Inequality: Changing Educational Attainment in Thirteen Countries. Boulder: Westview Press, pp. 7599.

Dronkers, J. (1995). The effects of the occupations of working mothers on the educational inequality. Educational Research and Evaluation, 1, 226246.

Erikson, R. (1984). Social class of men, women and families. Sociology, 18, 500514.

Farkas, G. (1996). Human Capital or Cultural Capital? Ethnicity and Poverty Groups in and Urban School District. New York: Aldine de Gruyter.

Furstenberg, F. F. and Kiernan, K. E. (2001). Delayed parental divorce: how much do children benefit? Journal of Marriage and Family, 63, 446457. 
Ganzeboom, H. B. G., Kalmijn, M. and Peschar, J. (1995). Het Nederlandse stratificatiepatroon in internationaal perspectief [The Dutch stratification pattern in international perspective]. In Dronker, J. and Ultee, W. C. (Eds.), Verschuivende Ongelijkheid in Nederland [Changing Inequality in the Netherlands]. Assen: Van Gorcum.

Ganzeboom, H. B. G. and Treiman, D. J. (2003). Three internationally standardized measures for compara tive research onoccupational status. In Hoffmeyer Zlotnik, J. H. and Wolf, C. (Eds.), Advances in Cross National Comparison: A European Working Book for Demographic and Socio Economic Variables. New York: Kluwer Academic Press, pp. 159193.

Ganzeboom, H. B. G. and Treiman, D. J. (2009). International stratification and mobility file. Available from <http://home.fsw.vu.nl/hbg.ganzeboom/ISMF/ index.htm $>$ [accessed 7 September 2009].

Gesthuizen, M., De Graaf, P. M. and Kraaykamp, G. (2005). The changing family background of the low educated in the Netherlands: socio demographic resources. European Sociological Review, 21, 441452.

Goldthorpe, J. H. (1983). Women and class analysis: in defense of the conventional view. Sociology, 17, 465488.

Korupp, S. E., Ganzeboom, H. B. G. and Van Der Lippe, T. (2002). Do mothers matter? A comparison of models of the influence of mothers' and fathers' educational and occupational status on children's educational attainment. Quality \& Quantity, 36, 1742.

Lareau, A. (1987). Social class differences in family school relationships: the importance of cul tural capital. Sociology of Education, 60, 7385.

Lucas, S. R. (2001). Effectively maintained inequality: education transitions, track mobility, and social background effects. American Journal of Sociology, 106, 16421690.

Marks, G. N. (2008a). Are father's or mother's socio economic characteristics more important influences on student performance? Recent international evi dence, Social Indicators Research, 85, 293309.
Marks, G. N. (2008b). Gender differences in the effects of socioeconomic background: recent cross national evidence. International Sociology, 23, 845863.

McDonald, G. W. (1977). Parental identification by the adolescent: a social power approach. Journal of Marriage and the Family, 39, 705719.

Menning, C. L. (2002). Absent parents are more than money: the joint effect of activities and financial support on youth's educational attainment. Journal of Family Issues, 23, 648671.

Mills, M. and Taht, K. (2010). Nonstandard work schedules and partnership quality: quantitative and qualitative findings. Journal of Marriage and the Family, 72, 860875.

Mulder, C. H. and Hooimeijer, P. (2002). Leaving home in the Netherlands: timing and first housing. Journal of Housing and the Built Environment, 17, 237268.

Muller, W. and Karle, W. (1993). Social selection in educational systems in Europe. European Sociological Review, 64, 123.

Murnane, R. J., Maynard, R. A. and Ohls, J. C. (1981). Home resources and children's achievement. Review of Economics and Statistics, 63, 367377.

Perry Jenkins, M. et al. (2007). Shift work, role overload, and the transition to parenthood. Journal of Marriage and Family, 69, 123138.

Sieben, I., Huinink, J. and De Graaf, P. M. (2001). Family background and sibling resemblance in edu cational attainment: trends in the former FRG, the former GDR, and the Netherlands. European Sociological Review, 17, 401430.

StataCorp (2011). Stata: Release 12. Statistical Software. College Station, TX: StataCorp LP.

Weiss, M. G. and Liss, M. B. (1988). Night shift work: job and family concerns. Journal of Social Behavior and Personality, 3, 279286.

White, L. and Keith, B. (1990). The effect of shift work on the quality and stability of marital relations. Journal of Marriage and the Family, 52, 453462.

Yamaguchi, K. (2002). Regression models with paramet rically weighted explanatory variables. Sociological Methodology, 32, 219245. 